UDC $547.944 / 945$

\title{
THE STRUCTURE OF TALATISAMINE
}

M. S. Yunusov and S. Yu. Yunusov

Khimiya Prirodnykh Soedinenii, Vol. 4, No. 3, pp. 198-199, 1968

The alkaloid talatisamine was first isolated by R. A. Konovalova and A. P. Orekhov from Aconitum talassicum M. Pop. [1]. The substance has the composition $\mathrm{C}_{24} \mathrm{H}_{39} \mathrm{NO}_{5}$ and the developed formula $\mathrm{C}_{19} \mathrm{H}_{23}\left(\mathrm{~N}-\mathrm{C}_{2} \mathrm{H}_{5}\right)(\mathrm{OH})_{2}(\mathrm{OCH})_{3}$ $[1,2]$. It has been suggested that one of the hydroxy groups of talatisamine is tertiary and the other primary or secondary [2]. Later, the functional composition of talatisamine was confirmed by its NMR spectrum. Oxidation of the alkaloid gave a ketone containing the carbonyl group in a five-membered ring [3]. On the basis of this information and also from biogenetic considerations, a lycoctonine skeleton with hydroxy groups in positions 8 and 19 and one of the methoxy groups at position 18 has been proposed for talatisamine [3].

In the present paper we give the results of a study of this alkaloid which have enabled us to determine its structure. The pyrolysis of diacetyltalatisamine gave two products. According to the NMR spectrum, the main reaction product retains one acetyl group (singlet at $8.09 \mathrm{\tau}$ ) and in the region of olefinic protons at 3.94-4.40 $\mathrm{T}$ there is an unresolved two-proton signal. The other product also contains one acetyl group (singlet at $8.08 \tau$ ) and in the region of olefinic protons of the NMR spectrum there is a one-proton doublet at $4.65 \tau$. This behavior on pyrolysis may be characteristic for alkaloids containing a methoxy group at C-14 in a lycoctonine skeleton with a hydroxy group in position 8 [4]. The formation of two products is connected with the appearance of a double bond between $\mathrm{C}-8$ and $\mathrm{C}-15$ (pyroacetyltalatisamine); a subsequent allyl rearrangement leads to the formation of isopyroacetyltalatisamine (double bond between $\mathrm{C}-14$ and $\mathrm{C}-15$, methoxy group at $\mathrm{C}-8$ ).

In the NMR spectrum of acetylbenzoyltalatisamine, the signal from the methyl of the acetyl group is strongly displaced toward the long-field region $(8.73 \tau)$. This shows that the benzoyl group is present in the alkaloid at $C-19$. This position of the secondary hydroxy group is confirmed by the appearance in the NMR spectrum of diacetyltalatisamine of the signal of a proton on a hydroxy group in the form of a poorly resolved triplet at 5. 29 $\tau$ [4]. In the NMR spectrum of isopyroacetyltalatisamine there is a well-defined signal in the form of a two-proton singlet at 7.00 $\mathrm{T}$, which shows the presence of a methoxy group at $\mathrm{C}-18$. When talatisamine was heated in $50 \%$ sulfuric acid for 2 hr, the starting material was recovered in $70 \%$ yield. This makes the presence of the third methoxy group in the alkaloid at C-6 unlikely [4]. In the mass spectrum of talatisamine, which is characteristic for alkaloids having a lycoctonine skeleton, the M-31 peak has the maximum intensity. This shows the presence in the base of a methoxy group at $C-1$ $[6,7]$. Thus, talatisamine possesses the structure given below.

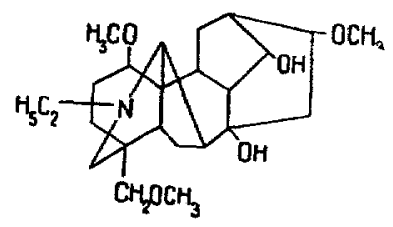

The NMR spectra were taken by M. R. Yagudaev on a JNM-4H-100/100 MHz in deuterochloroform with HMDS as internal standard. The values are given in the $\tau$ scale.

\section{REFERENCES}

1. R. A. Konovalova and A. P. Orekhov, ZhoKh, 10, 745, 1940.

2. S. Yu. Yunusov, E. V. Sichkova, and G. E. Potemkin, ZhOKh, 24, 2237, 1954.

3. M. A. Haimova, M. D. Palamareva, L. G. Grozdanova, N. M. Mollov, and P. P. Panov, Dokl. Bolg. $\mathrm{AN}, 20,193,1963$.

4. O. Achmatowicz, Y. Tsuda, Leo Marion, and T. Okamoto, Can. J. Chem., 43, 825, 1965.

5. Y. Tsuda and Leo Marion, Can. J. Chem., 41, 1634, 1963.

6. S. W. Pelletier and R. Aneja, Tetrah. Let., 6, 557, 1967. 